\title{
Uterine cervical carcinoma: Role of matrix metalloproteinases (Review)
}

\author{
MASSIMO LIBRA $^{1}$, AURORA SCALISI ${ }^{2}$, NADIA VELLA ${ }^{1}$, SILVIA CLEMENTI ${ }^{1}$, ROBERTO SORIO ${ }^{3}$, \\ FRANCA STIVALA $^{1}$, DEMETRIOS A. SPANDIDOS ${ }^{4}$ and CLORINDA MAZZARINO ${ }^{1}$ \\ ${ }^{1}$ Department of Biomedical Sciences, University of Catania; ${ }^{2}$ Secondary Prevention and Screening Gynaecological Unit, \\ AUSL 3, Catania; ${ }^{3}$ Medical Oncology Division C, Centro di Riferimento Oncologico, IRCCS, Aviano, Italy; \\ ${ }^{4}$ Department of Virology, Medical School, University of Crete, Heraklion, Greece
}

Received January 15, 2009; Accepted February 12, 2009

DOI: 10.3892/ijo_00000215

\begin{abstract}
Epidemiological and experimental studies have provided evidence that human papillomavirus (HPV) infection is a main player in the development of uterine cervical neoplasms. Migration of cancer cells from the origin tissue to surrounding or distant organs is essential for tumor progression. Many studies of tumor invasion and metastases have focused on the degradation of the extracellular matrix where matrix metalloproteinases (MMPs) play a central role. Two of these enzymes, MMP-2 and MMP-9, have been correlated with the processes of tumor cell invasion and metastasis in human cancers, including uterine neoplasms. It has been shown that the up-regulation of MMPs is associated with progression of cervical uterine neoplasms. This review describes the current understanding of MMP-2 and MMP-9 expression and activity in pre-cancer and cancer lesions of cervical uterine, which may open new strategies for diagnostic and therapeutic interventions.
\end{abstract}

\section{Contents}

1. Introduction

2. HPV infection in uterine cervical carcinoma

3. Matrix metalloproteinases in the progression of uterine cervical carcinoma

4. Conclusions

\section{Introduction}

Uterine cervical carcinoma is the second most common malignant tumor among women in the developing countries

Correspondence to: Dr Massimo Libra, Department of Biomedical Sciences, University of Catania, Via Androne 83, I-95124 Catania, Italy

E-mail:mlibra@unict.it

Key words: cervical carcinoma, human papillomavirus, matrix metalloproteinases
(1). Cervical intraepithelial neoplasia (CIN) is the preferred designation for the range of squamous intraepithelial abnormalities of the cervix that are associated with an increased risk of subsequent development of invasive squamous carcinoma. Traditionally, intraepithelial abnormalities are graded as CIN I, CIN II or CIN III depending on the degree of differentiation. Many cases of CIN are associated with infection by human papillomavirus (HPV) (2), confirmed by koilocytosis that may be identified in cervical biopsy specimens with or without CIN. In USA the traditional three tier CIN grading system used for the reporting of cervical cytology specimens has been replaced by a two tier grading system. This system, known as the Bethesda system, was developed in 1988 following a workshop sponsored by the National Cancer Institute which addressed the standardisation of cervical cytopathology reports (3). Premalignant cervical squamous abnormalities were divided into low grade squamous intraepithelial lesions (LSIL), which include features of HPV infection and CIN I (confined to the basal 1/3 of the epithelium), and high grade squamous intraepithelial lesions (HSIL), which include CIN II (confined to the basal $2 / 3$ of the epithelium) and CIN III (2/3 of the entire epithelium) that may involve the full thickness (carcinoma in situ) (4).

The Bethesda system and the histological diagnosis of CIN are relevant for the management of the disease. The severity of CIN is expressed by its microscopic grade, which influences treatment of the patient. This is understandable in view of the regression, persistence and progression figures of different CIN grades. An inadequacy of the grading by microscopic pathology is that it assesses exclusively epithelial features and usually only those visible with the standard hematoxylin-eosin staining, thereby not taking into account other possibly valuable information. Another serious disadvantage is due to the three distinct grades used in CIN (or two in SIL) that can easily give a faulty static impression of a solidified sculpture as if CIN or SIL were a static event, whereas in reality a CIN lesion is a dynamic process that can progress and persist but also regress. Compounding the above are the well-known issues of intraobserver and interobserver reproducibility, which, for grading of CIN, is far from perfect $(5,6)$. It is also difficult to distinguish CIN reliably from non-neoplastic lesions, resulting in either over- 
treatment or undertreatment $(7,8)$. These points emphasize the need for adjuvant methods to interpret the actual morphological impression of a CIN lesion in dynamic terms rather than in static morphological grades. Such adjunctive methods are also important for better distinction of CIN from nonneoplastic lesions and to predict accurately the risk for progression of low-grade and regression of high-grade CIN lesions. Even small improvements in prognostic accuracy will enormously reduce the number of patients erroneously or unnecessarily treated, as shown for CIN (2).

The cause of cervical cancer is still unknown. However, HPV infection represents the primary risk factor in cervical and vulvar cancer. Evidence of HPV is found in nearly $80 \%$ of cervical carcinomas (9). Many other risk factors have been demonstrated to influence the pathogenesis of cervical carcinoma, such as an early onset of sexual activity, parity, pregnancy, immunosuppression, smoking and a large number of life-time or recent sexual partners. Another well established risk factor for HPV infection is the mode of contraception, i.e. non-use of condom and long-term usage of oral contraception. Human immunodeficiency virus (HIV) infection reduces the immune system's ability to fight infection, including HPV, and increases the likelihood that precancerous cells will develop into frank cancer.

In the last ten years several studies have suggested that one of the mechanisms of cervical carcinoma progression is the increased expression of matrix-metalloproteinases (MMPs) in cervical tumor tissue and its association with tumor growth, metastasis, and recurrence (10-15) as a result of the degradation of extracellular matrix (ECM) components $(16,17)$.

\section{HPV infection in uterine cervical carcinoma}

Basic virology of HPV. The HPV virus is a small nonenveloped particle $55 \mathrm{~nm}$ in diameter. It has an icosahedral capsid composed of 72 capsomers, which contains at least two capsid proteins, L1 and L2. The virus is said to resemble a golf ball when viewed by electron microscopy. The HPV genome consists of a single molecule of double-stranded, circular DNA $(18,19)$. The genome is functionally divided into three regions. The first is a non-coding upstream regulatory region of 400-1,000 bp, which contains the long control region (LCR), or the upper regulatory region that regulate DNA replication by controlling the transcription of the open reading frames (OFRs). The second is an early region, consisting of ORFs E1, E2, E4, E5, E6, and E7, which are involved in viral replication. The third is a late region, which encodes the L1 and L2 structural proteins for the viral capsid. High-risk HPVs have different biological and biochemical properties important in cancer risk. Many lines of evidence suggest that once inside the host cell HPV DNA start replicating by employing host cell factors to regulate viral transcription and replication. The interaction of host cell factors with LCR region leads to the transcription of the viral E6 and E7 genes whose products deregulate the host cell growth cycle by binding and inactivating tumor suppressor proteins (p53 and pRB), cell cyclins, and cyclin-dependent kinases (20). The binding of HPV E7 to the cellular transcription factor E2F-1 resulting in the liberation of the factor allows the cell to enter $S$ phase of cell cycle. The outcome is stimulation of cellular DNA synthesis and cell proliferation. The E7 protein from low-risk HPV types binds pRB with decreased affinity (21). In addition other potential mechanisms contribute to the transformation such as methylation of viral and cellular DNA, telomerase activation and hormonal and immunogenetic factors. Progression to cancer generally takes place over a period of 10-20 years. Some lesions become cancerous more rapidly, sometimes within a year or two (22).

$H P V$ infection in the development of uterine cervical carcinoma. During the last decade, research on cervical cancer has elucidated the role of HPV in the pathogenesis of this malignancy (23). The link between genital HPV infections and cervical cancer was first demonstrated in the early 1980 s by Harold zur Hausen, a German virologist. The magnitude of the association between HPV and cervical cancer is higher than that one between smoking and lung cancer (24). Squamous cell carcinoma (SCC) is the most frequent cancer representing almost $90 \%$ of cervical malignancies. Accumulating evidence suggests that SCC is related to HPV infection, which is estimated to be the most common sexually transmitted disease, with a lifetime risk of $75 \%(25,26)$. Of 120 different HPV genotypes which have been discovered only 40 can infect the genital mucosa. Recurrent microtrauma allow HPVs to infect basal epithelial cells of the skin or inner lining of tissues. Following infection, HPV genes E1, E2, E4, E5, E6, and E7 are expressed and the viral DNA replicates from episomal DNA. The progression from pre-cancerous lesions to invasive cancer is associated with the integration of the HPV genome into the host chromosomes with loss of E2 and upregulation of E6 and E7 oncogene expression (Fig. 1). HPVs can be divided into high-risk and low-risk HPV types. Low-risk HPV types include types 6, 11, 42, 43, and 44. High-risk HPV types include types 16, 18, 31, 33, 34, 35, 39, $45,51,52,56,58,59,66,68$, and 70 . Infections with low-risk types can cause benign or low-grade cervical cell changes, genital warts, and recurrent respiratory papillomatosis $(27,28)$. High-risk HPV types act as carcinogens in the development of high grade cell abnormalities, cervical cancer and other anogenital cancers (29). Among these, four are most often found within the malignant cells of cervical cancers, with type 16 accounting for about half of the cases in the United States and Europe and types 18, 31, and 45 accounting for an additional $25-30 \%$ of cases (30). Many studies have shown that also adenocarcinoma of the cervix is related to HPV although the correlation is less pronounced and age-dependent (31).

HPV infection is extremely common among young sexually active women. Mostly the infection remains subclinical and self-limited (32), undergoing spontaneous clearance in a relatively short time, i.e., within months to two years $(19,33)$. Many studies have shown that only 5\% of these infections lead to squamous intraepithelial lesions (SILs) and even fewer develop to invasive cancer. The fact that only a small percentage of young women ( $<25$ years) develop cervical cancer is explained by a necessary 10 -year interval between the infection and cancer progression. Women with persistent ( $>6$ months) oncogenic HPV infection are at risk for progression to high-grade SIL (34). 


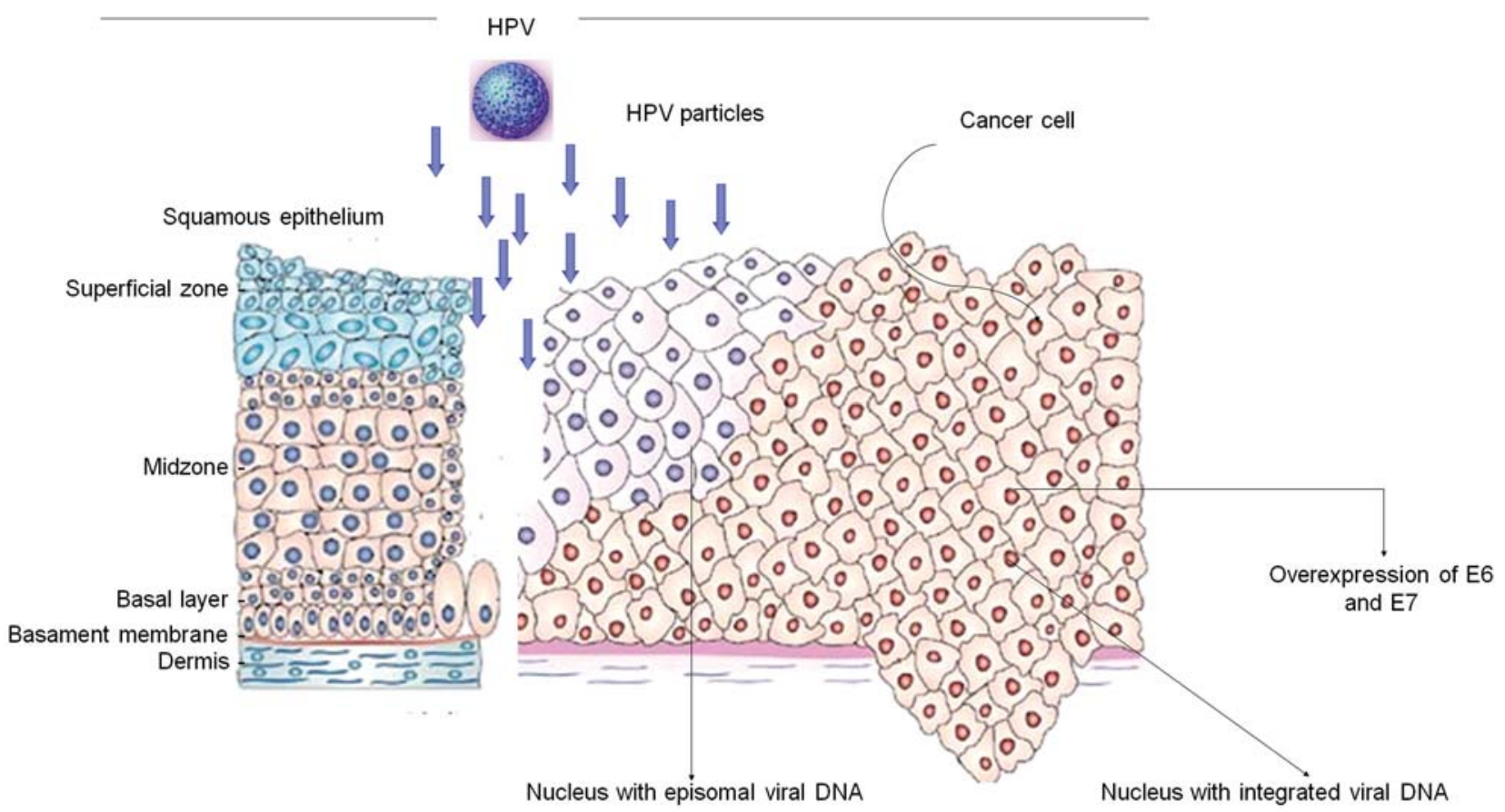

Figure 1. After human papillomavirus (HPV) infection, the early HPV genes (E1, E2, E4, E5, E6, E7) are expressed and the viral DNA replicates from episomal DNA. The progression from pre-cancerous lesions to invasive cancer is associated with the integration of the HPV genome into the host chromosomes with loss of E2 and upregulation of E6 and E7 oncogene expression.

\section{Matrix metalloproteinases in the progression of uterine cervical carcinoma}

Matrix metalloproteinases. MMPs are a family of metalloendopeptidases that cleave the protein components of the extracellular matrix (ECM) and thereby play a central role in tissue remodelling and degradation (35). In physiological conditions, the activities of MMPs are precisely regulated at the level of transcription, of activation of the pro-MMP precursor zymogens and of inhibition by endogenous inhibitors, tissue inhibitors of metalloproteinases (TIMPs) $(36,37)$. Most of the MMPs are synthesized as inactive latent enzymes and conversion to the active enzyme is generally mediated by activator systems that include plasminogen activator or the pro-hormone convertase, furin (38).

For many years MMPs were thought to function as regulators of ECM composition and to facilitate cell migration simply by removing barriers such as collagen. Many studies have shown that MMPs are implicated in the functional regulation of non-ECM molecules that include growth factors and their receptors, cytokines and chemokines, adhesion receptors and cell surface proteoglycans, and a variety of enzymes. Moreover MMPs play a significant role in the control of cellular interactions and response to their environment in physiological conditions that promote tissue turnover, such as normal development, or pathological, such as inflammation and cancer (39).

MMPs and cancer. The ability of cancer cells to migrate from the tissue of origin and metastasize to surrounding or distant organs is essential for tumor progression. Many studies of tumor invasion and metastases have focused on the degradation of the extracellular matrix and endothelial cell basement membrane $(16,40,41)$. It is becoming increasingly clear the central role of MMPs in the degradation of ECM (Fig. 2). Two of these enzymes, designated MMP-2 and MMP-9, are potent gelatinases and have been correlated with the processes of tumor cell invasion and metastasis. MMP-2 (gelatinase A) (42) and MMP-9 (gelatinase B), have been found in large quantities in cancer tissues $(43,44)$. Currently there is a growing evidence of their role in tumor progression $(43,45,46)$. Many different processes are involved in cancer cell invasion and wide spreading such as the transcriptional control of the genes encoding MMPs, their activation, and the production of their natural inhibitors TIMP-1 and TIMP-2 $(40,43)$. Substantial evidence suggests the importance of the MMPs/TIMPs ratio in tumor tissues e.g., the inhibition of tumor cell invasion and metastasis in animal models has been demonstrated using in vivo injections of TIMPs (47). During the many years following their discovery, MMPs have been revealed to have other significant functions in addition to the proteolytic activity. There are increasing data on their contribution to the tumor angiogenesis $(48,49)$ and their impact on cytokines regulation. Both inflammation and angiogenesis are exacerbated by increased production of chemokines/cytokines, growth factors, proteolytic enzymes, proteoglycans, lipid mediators and prostaglandins. It has been observed that approximately $15-20 \%$ of all malignancies are initiated or exacerbated by inflammation. The process of angiogenesis requires degradation and remodeling of ECM, cell migration and proliferation, and tube formation (50) and it can explain the relevant role played by MMPs in tumor growth and progression. The recruitment and infiltration of macrophages, called tumor-associated 


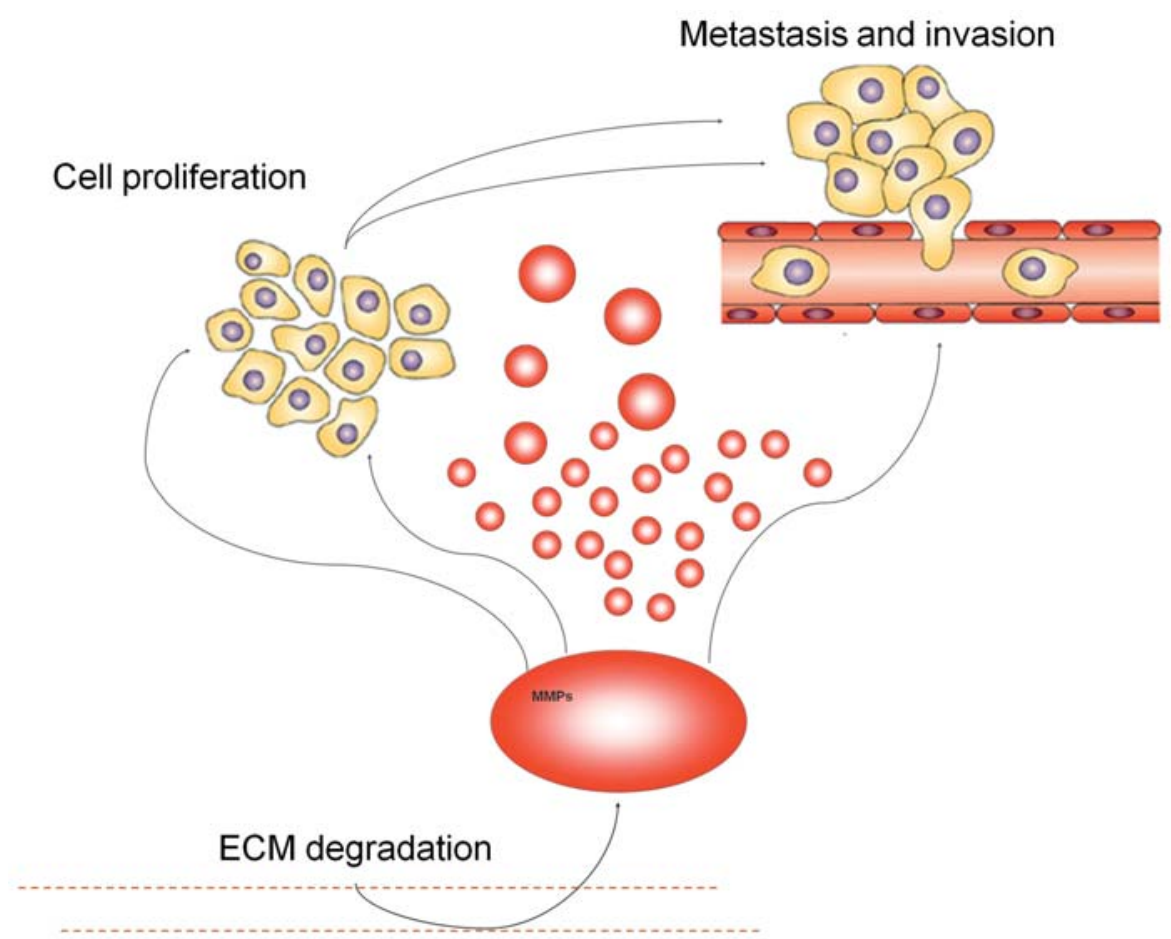

Figure 2. Matrix metalloproteinases (MMPs) promote cancer cell proliferation and invasion through the structural degradation of extracellular matrix (ECM) components.

macrophages, in the tumor microenvironment that activates them to support the malignant progression of cancer cells have also been reported.

MMPs in uterine cervical neoplasm. Overexpression of MMP-2 and MMP-9 has been observed in pre-cancer and cancer lesions of the cervical uterine (Table I). During the last decades progress in research on enzyme activities showed the potential significance of MMP-2 and MMP-9 in the progression of cervical uterine cancer suggesting their prognostic value (14,15,51-65). Sheu et al demonstrated that MMP-2 and MMP-9 were overexpressed in $>90 \%$ of squamous cell carcinomas (SCC) and $83-100 \%$ of HSIL, but were less frequently expressed in LSIL and normal squamous epithelium (13\%). MMP-1, MMP-14, and MMP-15 were detected in $55-81 \%$ of SCC cases, and MMP-1 was detected in $39 \%$ of HSIL (14). Many lines of evidence show that the activity of MMP-9 tends to increase from normal cervix to HSIL and SCC, and more advanced stages (64-66). Cervical cancer provides a useful model to study the relationship of MMPs and TIMPs (67-69) to tumor behavior. First of all the well characterized microinvasive carcinoma of the cervix, with its excellent outcome, can be compared with more deeply invasive tumors which invariably evolve from the microinvasive state, and have a poorer prognosis. Many studies have shown a 1:1 ratio of MMPs:TIMPs in early cervical cancers (11). It is explained by the fact that tumor progression may select for cells expressing MMPs and do not express TIMP messages by promoting tumor cell growth. HPV infection is an essential step in the development of cervical cancers and transfection with the E6 and E7 HPV ORFs is sufficient to induce malignant transformation in normal squamous cells in vitro, but it is not known if these or other
Table I. Expression of MMP-2 and MMP-9 in uterine cervical neoplasms.

\begin{tabular}{lccc}
\hline & \multicolumn{2}{c}{$\%$ of cases expressing MMPs } & \\
\cline { 2 - 3 } $\begin{array}{l}\text { Diagnosis } \\
\text { (no. of cases) }\end{array}$ & MMP-2 & MMP-9 & Refs. \\
\cline { 2 - 3 } SCC (31) & 90 & 87 & $(14)$ \\
HSIL (23) & 83 & 83 & $(14)$ \\
LSIL (8) & 13 & 13 & $(14)$ \\
SCC (80) & 46 & n.d. & $(15)$ \\
SCC (160) & 42 & 31 & $(57)$ \\
SCC (15) & 100 & n.d. & $(60)$ \\
HSIL (18) & 61 & n.d. & $(60)$ \\
LSIL (11) & 0 & n.d. & $(60)$ \\
SCC (49) & 84 & n.d. & $(61)$ \\
HSIL (10) & 100 & n.d. & $(61)$ \\
SCC (18) & n.d. & 72 & $(62)$ \\
HSIL (5) & n.d. & 50 & $(62)$ \\
Adenocarcinoma (18) & 94 & 94 & $(63)$ \\
SCC (24) & n.d. & 50 & $(64)$ \\
HSIL (30) & n.d. & 86 & $(65)$ \\
LSIL (13) & n.d. & 54 & $(65)$ \\
\hline
\end{tabular}

Abbreviations: SCC, squamous cell carcinoma; LSIL, low grade squamous intraepithelial lesions; HSIL, high grade squamous intraepithelial lesions; n.d., not determined. 
HPV proteins can influence MMP or TIMPs transcripts or enzyme activity. Recent findings suggests that HPV E6 and E7 transcription correlates with MMPs and TIMPs transcription $(11,70)$. Although early studies obtained contrary outcomes, recent research has shown that EBV proteins may up-regulate MMP-1 expression in nasopharyngeal carcinoma, suggesting that other viral proteins may also regulate MMP expression (71).

Many studies have also observed that MMPs, and in particular MMP-2 and MMP-9, are expressed in stromal cells and inflammatory cells around tumors (72). These findings suggest the importance of these proteases in the pathogenesis of cancer. Of various inflammatory cell types infiltrating the tumor area in response to inflammatory stimuli, tumorsupporting macrophages, and tumor-associated macrophages (TAM), are thought to play key roles in further production of various growth factors, angiogenic factors, proteinases, chemokines and cytokines, through cross-talk with cancer cells and other tumor stromal cells (73). These factors stimulate cell migration/motility, proliferation, survival, angiogenesis and metastasis, resulting in a dynamic environment that favors the progression of cancer $(48,49,74,75)$. For example it has been recently observed that MMP-9 plays a central role in the cleavage of certain cytokine receptors (i.e., interleukin $2 \mathrm{R} \alpha$ ) on tumor-infiltrating lymphocytes derived from human cervical cancer $(76,77)$. Other evidence shows that MMPs activate tumor necrosis factor $\alpha$ or inactivate interleukin $1 \beta$, which may potentiate tumor progression by regulating the activity of these immunoregulatory cytokines at the site of tumor invasion (78).

\section{Conclusions}

Several studies have provided evidence that HPV infection plays an important role in the development of uterine cervical neoplasm. In June of 2006, the Food and Drug Administration (FDA) approved a cervical cancer vaccine for girls and women between the ages of 9 and 26. This vaccine should dramatically decrease the risk of uterine cervical cancer in the near future. Numerous studies support the possibility that overexpression of MMPs promotes tumor growth and metastasis in uterine cervical carcinoma. In particular, overexpression and activity of MMP-2 and MMP-9 has been observed and their prognostic significance in the progression of cervical uterine cancer has been proven. An appreciation of how these enzymes are linked to progression of this disease may improve diagnostic and therapeutic strategies.

\section{Acknowledgments}

This work was supported in part by the Lega Italiana per la Lotta contro i Tumori (M.L., A.S., and F.S.).

\section{References}

1. Parkin DM, Bray F, Ferlay J and Pisani P: Global cancer statistics, 2002. CA Cancer J Clin 55: 74-108, 2005.

2. Herrington CS: Human papillomaviruses and cervical neoplasia I. Classification, virology, pathology and epidemiology. J Clin Pathol 47: 1066-1071, 1994.

3. Solomon D: The 1988 Bethesda system for reporting cervical/ vaginal cytological diagnoses. Acta Cytol 33: 567-574, 1989.
4. Petignat $\mathrm{P}$ and Roy M: Diagnosis and management of cervical cancer. BMJ 335: 765-768, 2007.

5. Heatly MK: How should we grade CIN? Histopathology 40: 377-390, 2002.

6. Grenko RT, Abendroth CS, Frauenhoffer EE, Ruggiero FM and Zaino RJ: Variance in the interpretation of cervical biopsy specimens obtained for atypical squamous cells of undetermined significance. Am J Clin Pathol 114: 735-740, 2000.

7. Nafussi AI and Colquhoun MK: Mild cervical intraepithelial neoplasia (CIN-1) - a histological overdiagnosis. Histopathology 17: 557-561, 1990.

8. Creagh T, Bridger JE, Kupek E, Fish DE, Martin-Bates E and Wilkins MJ: Pathologist variation in reporting cervical borderline epithelial abnormalities and cervical intraepithelial neoplasia. J Clin Pathol 48: 59-60, 1995.

9. Beaudenon S and Huibregtse JM: HPV E6, E6AP and cervical cancer. BMC Biochem 9 (Suppl. 1): S4, 2008.

10. Mocchegiani E, Ciavattini A, Santarelli L, Tibaldi A, Muzzioli M, Bonazzi P, Giacconi R, Fabris N and Garzetti GG: Role of zinc and alpha-2 macroglobulin on thymic endocrine activity and on peripheral immune efficiency (natural killer activity and interleukin-2) in cervical carcinoma. Br J Cancer 79: 244-250, 1999.

11. Nuovo GJ, MacConnell PB, Simsir A, Valea F and French DL: Correlation of the in situ detection of polymerase chain reactionamplified metalloproteinase complementary DNAs and their inhibitors with prognosis in cervical carcinoma. Cancer Res 55: 267-275, 1995.

12. Gilles C, Polette M, Piette J, Munaut C, Thompson EW, Birembaut P and Foidart JM: High level of MT-MMP expression is associated with invasiveness of cervical cancer cells. Int $\mathbf{J}$ Cancer 65: 209-213, 1996.

13. Garzetti GG, Ciavattini A, Lucarini G, Goteri G, De Nictolis M and Biagini G: Microinvasive cervical carcinoma and cervical intraepithelial neoplasia: biologic significance and clinical implications of 72-kDa metalloproteinase immunostaining. Gynecol Oncol 61: 197-203, 1996.

14. Sheu BC, Lien HC, Ho HN, Lin HH, Chow SN, Huang SC and Hsu SM: Increased expression and activation of gelatinolytic matrix metalloproteinases is associated with the progression and recurrence of human cervical cancer. Cancer Res 63: 6537-6542, 2003.

15. Wang PH, Ko JL, Tsai HT, Yang SF, Han CP, Lin LY and Chen GD: Clinical significance of matrix metalloproteinase-2 in cancer of uterine cervix: a semiquantitative study of immunoreactivities using tissue array. Gynecol Oncol 108: 533-542, 2008.

16. Egeblad M and Werb Z: New functions for the matrix metalloproteinases in cancer progression. Nat Rev 2: 163-176, 2002.

17. Kato Y, Yamashita T and Ishikawa M: Relationship between expression of matrix metalloproteinase- 2 and matrix metalloproteinase- 9 and invasion ability of cervical cancer cells. Oncol Rep 9: 565-569, 2002.

18. Lace MJ, Anson JR, Turek LP and Haugen TH: Functional mapping of the human papillomavirus type $16 \mathrm{E} 1$ cistron. J Virol 82: 10724-10734, 2008.

19. De Villiers EM, Fauquet C, Broker TR, Bernard HU and zur Hausen H: Classification of papillomaviruses. Virology 324: 17-27, 2004.

20. Syrjänen SM and Syrjänen KJ: New concepts on the role of human papillomavirus in cell cycle regulation. Ann Med 31: 175-187, 1999

21. Thomas M, Pim D and Banks L: The role of the E6-p53 interaction in the molecular pathogenesis of HPV. Oncogene 18: 7690-7000, 1999.

22. Holowaty P, Miller AB, Rohan T and To T: Natural dysplasia of the uterine cervix. J Natl Cancer Inst 91: 252-258, 1999.

23. Chan JK and Bereck JS: Impact of the human papilloma vaccine on cervical cancer. J Clin Oncol 25: 2975-2982, 2007.

24. Franco EL: Cancer causes revisited: human papillomavirus and cervical neoplasia. J Natl Cancer Inst 87: 779-780, 1995.

25. Parkin DM: The global health burden of infection-associated cancers in the year 2002. Int J Cancer 118: 3030-3044, 2006.

26. Davey DD, Neal MH, Wilbur DC, Colgan TJ, Styer PE and Mody DR: Bethesda 2001 implementation and reporting rates: 2003 practices of participants in the College of America Pathologists Interlaboratory Comparison Program in Cervicovaginal Cytology. Arch Phatol Lab Med 128: 1224-1229, 2004.

27. NIH Consensus Statement. Cervical cancer. NIH Consens Statement 14: 1-38, 1996. 
28. World Health Organization. IARC monograph on the evaluation of carcinogenic risks to humans: human papillomaviruses. 1995. IARC, Lyons, 2000.

29. Munoz N, Bosch FX, De Sanjose S, Herrero R, Castellsagué X, Shah KV, Snijders PJ and Meijer CJ: International Agency for Research on Cancer Multicenter Cervical Cancer Study Group. Epidemiologic classification of human papillomavirus types associated with cervical cancer. N Engl J Med 348: 518-527, 2003.

30. Harro CD, Pang Y-YS, Roden RBS, Hildesheim A, Wang Z, Reynolds MJ, Mast TC, Robinson R, Murphy BR, Karron RA, Dillner J, Schiller JT and Lowy DR: Safety and immunogenicity trial in adult volunteers of a human papillomavirus 16 L1 virus-like particle vaccine. J Natl Cancer Inst 93: 284-292, 2001.

31. Andersson S, Rylander E, Larsson B, Strand A, Silfversvard C and Wilander E: The role of human papillomavirus in cervical adenocarcinoma carcinogenesis. Eur J Cancer 37: 246-250, 2001.

32. Jones BA and Novis DA: Cervical biopsy-cytology correlation: a college of American Phathologists Q-Probes study of 22,439 correlations in 348 laboratories. Arch Pathol Lab Med 120: 523-531, 1996.

33. Clifford GM, Smith JS, Aguado T and Franceschi S: Comparison of HPV type distribution in high-grade cervical lesions and cervical cancer: a meta-analysis. Br J Cancer 89: 101-105, 2003.

34. Cates W Jr: Estimates of the incidence and prevalence of sexually transmitted diseases in the United States: American Social Health Association Panel. Sex Transm Dis 26: S2-S7, 1999.

35. Stamenkovic I: Extracellular matrix remodelling: the role of matrix metalloproteinases. J Pathol 200: 448-464, 2003.

36. Nagase H: Zinc Metalloproteases in Health and Disease Hooper NM (ed). Taylor \& Francis, London, pp153-204, 1996.

37. Fini ME, Cook JR, Mohan R and Brinckerhoft CE: Matrix Metalloproteinases. Parks WC and Mecham RP (eds). Academic Press, San Diego, pp299-356, 1998.

38. Malemud CJ: Matrix metalloproteinases (MMPs) in health and disease: an overview. Front Biosci 11: 1696-1701, 2006.

39. Beaudeux JL, Philippe G, Bruckert E, Foglietti MJ and Chapman MJ. Matrix metalloproteinases, inflammation and atherosclerosis: therapeutic perspectives. Clin Chem Lab Med 42: 121-131, 2004

40. Reich R, Thompson E, Iwamoto Y, Martin OR, Deason JR, Fuller OC and Miskin R: Effects of inhibitors of plasminogen activator, serine proteinases, and collagenase IV on the invasion of basement membrane by metastatic cells. Cancer Res 48: 3307-33121, 1988.

41. Liotta LA, Steeg PS and Stetler-Stevenson WO: Cancer metastasis and angiogenesis: an imbalance of positive and negative regulation. Cell 64: 327-336, 1991.

42. Fernandes T, De Angelo-Andrade LA, Morais SS, Pinto GA, Chagas CA, Maria-Engler SS and Zeferino LC: Stromal cells play a role in cervical cancer progression mediated by MMP-2 protein. Eur J Gynaecol Oncol 29: 341-344, 2008

43. Liotta LA, Tryggvason K, Garbisa S, Hart I, Foltz CM and Shafie S: Metastatic potential correlates with enzymatic degradation of basement membrane collagen. Nature 284: 67-68, 1980 .

44. Giannelli G, Falk-Marzillier J, Schiraldi O, Stetler-Stevenson WG and Quaranta V: Induction of cell migration by matrix metalloproteinase-2 cleavage of laminin-5. Science 277: 225-228, 1997.

45. Turpeenniemi-Hujanen T, Thorgeirsson UP, Hart IR, Grant SS and Liotta LA: Expression of collagenase IV (basement membrane collagenase) activity in murine tumor cell hybrids that differ in metastatic potential. J Natl Cancer Inst 75: 99-108, 1985

46. Stetler-Stevenson WG, Hewitt R and Corcoran M: Matrix metalloproteinases and tumor invasion: from correlation and causality to the clinic. Semin Cancer Biol 7: 147-154, 1996.

47. McDonnell S and Matrisian LM: Stromelysin in tumor progression and metastasis. Cancer Metastasis Rev 9: 305-319, 1990.

48. Fisher C, Gilbertson-Beadling S, Powers EA, Petzold G, Poorman R and Mitchell MA: Interstitial collagenase is required for angiogenesis in vitro. Dev Biol 162: 499-510, 1994.
49. Hashimoto G, Inoki I, Fujii Y, Aoki T, Ikeda E and Okada Y: Matrix metalloproteinases cleave connective tissue growth factor and reactivate angiogenic activity of vascular endothelial growth factor 165. J Biol Chem 277: 36288-36295, 2002.

50. Carmeliet P: Mechanisms of angiogenesis and arteriogenesis. Nat Med 6: 389-395, 2005

51. Gaiotto MA, Focchi J, Ribalta JL, Stávale JN, Baracat EC, Lima GR and Guerreiro Da Silva ID: Comparative study of MMP-2 (matrix metalloproteinase 2) immune expression in normal uterine cervix, intraepithelial neoplasias, and squamous cells cervical carcinoma. Am J Obstet Gynecol 190: 1278-1282, 2004.

52. Argüello-Ramírez J, Pérez-Cárdenas E, Delgado-Chávez R, Solorza-Luna G,Villa-Treviño S and Arenas-Huertero F: Matrix metalloproteinases-2, -3 , and -9 secreted by explants of benign and malignant lesions of the uterine cervix. Int $J$ Gynecol Cancer 14: 333-340, 2004

53. Sato T, Sakai T, Noguchi Y, Takita M, Hirakawa S and Ito A: Tumor-stromal cell contact promotes invasion of human uterine cervical carcinoma cells by augmenting the expression and activation of stromal matrix metalloproteinases. Gynecol Oncol 92: 47-56, 2004.

54. Ahmed MI, Salahy EE, Tawfiq H, Khalifa A and Hassan MM: Matrix metalloproteinase-2, squamous cell carcinoma antigen, and tissue polypeptide-specific antigen expression in Egyptian patients with cervical carcinoma: relationship with prognosis. Dis Markers 20: 333-343, 2004.

55. Yang SF, Wang PH, Lin LY, Ko JL, Chen GD, Yang JS, Lee HS and Hsieh YS: A significant elevation of plasma level of matrix metalloproteinase-9 in patients with high-grade intraepithelial neoplasia and early squamous cell carcinoma of the uterine cervix. Reprod Sci 14: 710-718, 2007.

56. Baltazar-Rodriguez LM, Anaya-Ventura A, Andrade-Soto M, Monrroy-Guizar EA, Bautista-Lam JR, Jonguitud-Olguin G, Cepeda-Lopez FR, Centeno-Aguilar VA, Gonzalez-Hernandez NA, Soriano-Hernández AD, Ramirez-Flores M, Lugo-Trampe A, Rodriguez-Sanchez IP, Newton-Sanchez OA and DelgadoEnciso I: Polymorphism in the matrix metalloproteinase-2 gene promoter is associated with cervical neoplasm risk in Mexican women. Biochem Genet 46: 137-144, 2008.

57. Rauvala M, Aglund K, Puistola U, Turpeenniemi-Hujanen T, Horvath G, Willén R and Stendahl U: Matrix metalloproteinases-2 and -9 in cervical cancer: different roles in tumor progression. Int J Gynecol Cancer 16: 1297-1302, 2006.

58. Nasr M, Ayyad SB, El-Lamie IK and Mikhail MY: Expression of matrix metalloproteinase- 2 in preinvasive and invasive carcinoma of the uterine cervix. Eur J Gynaecol Oncol 26: 199-202, 2005.

59. Yoshida H, Sumi T, Hyun Y, Nakagawa E, Hattori K, Yasui T, Morimura M, Honda K, Nakatani T and Ishiko O: Expression of survivin and matrix metalloproteinases in adenocarcinoma and squamous cell carcinoma of the uterine cervix. Oncol Rep 10: 45-49, 2003.

60. Brummer O, Böhmer G, Hollwitz B, Flemming P, Petry KU and Kühnle H: MMP-1 and MMP-2 in the cervix uteri in different steps of malignant transformation - an immunohistochemical study. Gynecol Oncol 84: 222-227, 2002.

61. Davidson B, Goldberg I, Kopolovic J, Lerner-Geva L, Gotlieb WH, Ben-Baruch G and Reich R: MMP-2 and TIMP-2 expression correlates with poor prognosis in cervical carcinoma a clinicopathologic study using immunohistochemistry and mRNA in situ hybridization. Gynecol Oncol 73: 372-382, 1999.

62. Davidson B, Goldberg I, Kopolovic J, Lerner-Geva L, Gotlieb WH, Weis B, Ben-Baruch G and Reich R: Expression of matrix metalloproteinase- 9 in squamous cell carcinoma of the uterine cervix-clinicopathologic study using immunohistochemistry and mRNA in situ hybridization. Gynecol Oncol 72: 380-386, 1999.

63. Davidson B, Goldberg I, Liokumovich P, Kopolovic J, Gotlieb WH, Lerner-Geva L, Reder I, Ben-Baruch G and Reich R: Expression of metalloproteinases and their inhibitors in adenocarcinoma of the uterine cervix. Int $\mathrm{J}$ Gynecol Pathol 17: 295-301, 1998.

64. Talvensaari-Mattila A, Turpeenniemi-Hujanen T and Puistola U: Matrix metalloproteinase 9 and relapse in patients with early stage squamous cervical carcinoma. Int J Gynaecol Obstet 91: 75-76, 2005.

65. Talvensaari-Mattila A and Turpeenniemi-Hujanen T: Matrix metalloproteinase 9 in the uterine cervix during tumor progression. Int J Gynaecol Obstet 92: 83-84, 2006. 
66. Giraudo E, Inoue M and Hanahan D: An amino-bisphosphonate targets MMP-9-expressing macrophages and angiogenesis to impair cervical carcinogenesis. J Clin Invest 114: 623-633, 2004.

67. Lizarraga F, Espinosa M, Maldonado V and Melendez-Zajgla J: Tissue inhibitor of metalloproteinases-4 is expressed in cervical cancer patients. Anticancer Res 25: 623-627, 2005.

68. Zhang Y, Qian H, Lin C, Lang J, Xiang Y, Fu M, Zhang X and Liang X: Adenovirus carrying TIMP-3: a potential tool for cervical cancer treatment. Gynecol Oncol 108: 234-240, 2008

69. Ramer R and Hinz B: Inhibition of cancer cell invasion by cannabinoids via increased expression of tissue inhibitor of matrix metalloproteinases-1. J Natl Cancer Inst 100: 59-69, 2008.

70. Da Silva Cardeal LB, Brohem CA, Corrêa TC, Winnischofer SM, Nakano F, Boccardo E, Villa LL, Sogayar MC and MariaEngler SS: Higher expression and activity of metalloproteinases in human cervical carcinoma cell lines is associated with HPV presence. Biochem Cell Biol 84: 713-719, 2006

71. Lu J, Chua H-H, Chen S-Y, Chen J-Y and Tsai C-H: Regulation of matrix metalloproteinase-1 by Epstein-Barr virus proteins. Cancer Res 63: 256-262, 2003.

72. Tellier E, Nègre-Salvayre A, Bocquet B, Itohara S, Hannun YA, Salvayre R and Augé N: Role for furin in tumor necrosis factor alpha-induced activation of the matrix metalloproteinase/ sphingolipid mitogenic pathway. Mol Cell Biol 27: 2997-3007, 2007
73. Kanda K, Ueda M, Futakuchi H, Yamaguchi H, Mori K, Terai $\mathrm{Y}$ and Ueki M: Transcriptional expression of the genes implicated in angiogenesis and tumor invasion in cervical carcinomas. Gynecol Oncol 98: 453-461, 2005.

74. Itoh T, Tanioka M, Yoshida H, Yoshioka T, Nishimoto H and Itohara S: Reduced angiogenesis and tumor progression in gelatinase A-deficient mice. Cancer Res 58: 1048-1051, 1998.

75. Stetler-Stevenson WH: Matrix metalloproteinases in angiogenesis: a moving target for therapeutic intervention: J Clin Invest 103: 1237-1241, 1999.

76. Sheu B-C, Lin R-H, Ho H-N and Huang S-C: Down-regulation of $\mathrm{CD} 25$ expression on activated tumour-infiltrating lymphocytes derived from human cervical carcinoma. Hum Immunol 56: 39-47, 1997.

77. Sheu B-C, Hsu S-M, Ho H-N, Lien H-C, Huang S-C and Lin R-H: A novel role of metalloproteinase in cancer-mediated immunosuppression. Cancer Res 61: 237-242, 2001.

78. Ito A, Mukaiyama A, Itoh Y, Nagase H, Thogersen IB, Enghild JJ, Sasaguri Y and Mori Y: Degradation of interleukin-1ß by matrix metalloproteinases. J Biol Chem 271: 14657-14660, 1996. 